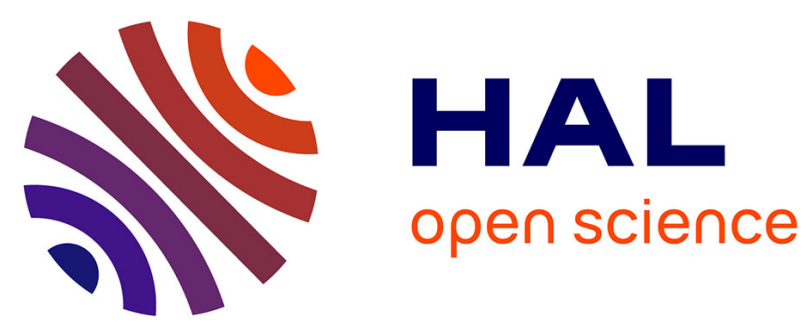

\title{
High catalytic efficiency of palladium nanoparticles immobilized in a polymer membrane containing poly(ionic liquid) in Suzuki-Miyaura cross-coupling reaction
}

Yingying Gu, Isabelle Favier, Christian Pradel, Douglas L. Gin, Jean-Francois Lahitte, Richard D. Noble, Montserrat Gómez, Jean-Christophe Remigy

\section{To cite this version:}

Yingying Gu, Isabelle Favier, Christian Pradel, Douglas L. Gin, Jean-Francois Lahitte, et al.. High catalytic efficiency of palladium nanoparticles immobilized in a polymer membrane containing poly(ionic liquid) in Suzuki-Miyaura cross-coupling reaction. Journal of Membrane Science, 2015, vol. 492, pp.331-339. 10.1016/j.memsci.2015.05.051 . hal-01286001

\section{HAL Id: hal-01286001 https://hal.science/hal-01286001}

Submitted on 10 Mar 2016

HAL is a multi-disciplinary open access archive for the deposit and dissemination of scientific research documents, whether they are published or not. The documents may come from teaching and research institutions in France or abroad, or from public or private research centers.
L'archive ouverte pluridisciplinaire HAL, est destinée au dépôt et à la diffusion de documents scientifiques de niveau recherche, publiés ou non, émanant des établissements d'enseignement et de recherche français ou étrangers, des laboratoires publics ou privés. 


\section{OATAO \\ Open Archive Toulouse Archive Ouverte}

\section{Open Archive TOULOUSE Archive Ouverte (OATAO)}

OATAO is an open access repository that collects the work of Toulouse researchers and makes it freely available over the web where possible.

This is an author-deposited version published in : http://oatao.univ-toulouse.fr/ Eprints ID : 15578

To link to this article : DOI:10.1016/j.memsci.2015.05.051

URL : http://dx.doi.org/10.1016/j.memsci.2015.05.051

To cite this version : Gu, Yingying and Favier, Isabelle and Pradel, Christian and Gin, Douglas L. and Lahitte, Jean-Francois and Noble, Richard D. and Gómez, Montserrat and Remigy, Jean-Christophe High catalytic efficiency of palladium nanoparticles immobilized in a polymer membrane containing poly(ionic liquid) in Suzuki-Miyaura cross-coupling reaction. (2015) Journal of Membrane Science, vol. 492. pp.331-339. ISSN 0376-7388

Any correspondence concerning this service should be sent to the repository administrator: staff-oatao@listes-diff.inp-toulouse.fr 


\title{
High catalytic efficiency of palladium nanoparticles immobilized in a polymer membrane containing poly(ionic liquid) in Suzuki-Miyaura cross-coupling reaction
}

\author{
Yingying $\mathrm{Gu}^{\mathrm{a}}$, Isabelle Favier ${ }^{\mathrm{b}}$, Christian Pradel ${ }^{\mathrm{b}}$, Douglas L. Gin ${ }^{\mathrm{c}, \mathrm{d}}$, Jean-François Lahitte ${ }^{\mathrm{a}}$, \\ Richard D. Noble ${ }^{\mathrm{c}}$, Montserrat Gómez ${ }^{\mathrm{b}}$, Jean-Christophe Remigy ${ }^{\mathrm{a}, *}$ \\ a Université de Toulouse; INPT, UPS, UMR CNRS 5503; Laboratoire de Génie Chimique 118 Route de Narbonne, F-31062 Toulouse, France \\ b Laboratoire Hétérochimie Fondamentale et Appliquée, UMR CNRS 5069, Université Paul-Sabatier, 31062 Toulouse cedex 9, France \\ ${ }^{\mathrm{c}}$ Department of Chemistry \& Biochemistry, University of Colorado, Boulder, CO 80309, United States \\ ${ }^{\mathrm{d}}$ Department of Chemical \& Biological Engineering, University of Colorado, Boulder, CO 80309, United States
}

Keywords:

Catalytic membrane

Palladium nanoparticles

Flow-through membrane reactor

Imidazolium-based ionic liquid

Suzuki-Miyaura cross-coupling

\begin{abstract}
A B S T R A C T
The elaboration of a polymeric catalytic membrane containing palladium nanoparticles is presented. The membrane was prepared using a photo-grafting process with imidazolium-based ionic liquid monomers as modifying agent and microPES ${ }^{\circledR}$ as support membrane. Ionic liquid serves as a stabilizer and immobilizer for the catalytic species, i.e. palladium nanoparticles. The Suzuki-Miyaura cross-coupling reaction was carried out on the catalytic membrane in flow-through configuration. Complete conversion was achieved in $10 \mathrm{~s}$ through one single filtration, without formation of byproducts. The apparent reaction rate constant was three orders of magnitude greater than in a batch reactor. No catalyst leaching was detected. This membrane offers the possibility of continuous production with no need for a separation step of the catalyst from the reaction medium.
\end{abstract}

\section{Introduction}

Catalytic membranes have found applications in the field of fine chemistry, petrochemical industry, water treatment, etc. [1-4]. Unlike a batch reactor whose conversion rate slows down with time, a catalytic membrane gives constant conversion over time as it can be considered as a plug-flow reactor. Another advantage of a catalytic membrane is that no separation of the catalyst from the reaction medium is necessary for reuse with the catalyst immobilized inside the membrane. The mass-transfer resistance towards the catalyst is also expected to be eliminated by forcing reactants to flow through membrane pores [5]. The intensive contact between the reactant mixture and the catalyst may lead to a higher apparent conversion rate [6].

Most catalytic membranes to the date are based on inorganic materials, with applications for steam reforming of methane, alkane dehydrogenation, oxidative coupling of methane, etc. [6-10]. Polymeric membranes used in membrane reactors, however, can have some advantages over the expensive inorganic membranes, namely

\footnotetext{
* Correspondence to: Laboratoire de Génie Chimique, Université Paul Sabatier 31062 Toulouse Cedex 09, France. Tel.: +33561557618.

E-mail address: remigy@chimie.ups-tlse.fr (J.-C. Remigy).
}

lower production costs, crack-free thin membranes, and large scale production [7]. However, polymeric membranes should be used under mild conditions $\left(<150^{\circ} \mathrm{C}\right)$, and thus require a highly active catalyst to ensure good reactivity. Metallic nanoparticles (MNP) have shown very interesting catalytic activity thanks to their high surface/ volume ratio [11]. In general, their activity increases when they get smaller because of higher surface/volume ratio and higher fraction of the low-coordinated corner and edge atoms. The high surface energy of MNPs makes them thermodynamically unstable. The presence of appropriate stabilizers is necessary to prevent their aggregation, which usually results in loss of activity. The stabilization of MNPs can be accomplished by a steric effect [12], an electrostatic effect [13], a combination of both (electrosteric effect) [14], or a ligand [15].

$\mathrm{H}$. Hagiwara et al., reported the immobilization of palladium acetate in an ionic liquid in silica pores [16]. Since no chemical bonding exists between the ionic liquid and silica, reaction can be carried out only in a hydrocarbon solvent to prevent removal of the ionic liquid layer from the silica. Nevertheless, palladium leaching from the silica support was still observed [16]. In our case, poly(ionic liquid) (polyIL) was chemically grafted to microPES $^{\circledR}$ support membrane to stabilize palladium nanoparticles by electrosteric effect so that leaching of both nanoparticles and ionic liquid could be effectively prevented. The well-defined palladium 
nanoparticles immobilized inside the membrane provided catalytically active sites for the organic transformations envisaged [17].

\section{Materials and methods}

For the general aspects related to the Experimental part, see the Supplementary information.

\subsection{Synthesis and characterization of ionic liquids $\boldsymbol{a}$ and $\boldsymbol{b}$}

Imidazolium-based ionic liquids (a non-cross-linking monomer a and a cross-linker b) used for MNP stabilization were synthesized according to Scheme 1 . Detailed syntheses of compound $\mathbf{i}$ and ii were previously reported [18]. The methodologies followed for the synthesis of the monomer $\mathbf{a}$ and the cross-linker $\mathbf{b}$ and their full characterization are described in the Supplementary information.

\subsection{Preparation of the catalytic membrane}

\subsubsection{Grafting of poly(Ionic liquid)s on the PES (polyethersulfone) support membrane}

A round-shaped membrane was cut from a microPES ${ }^{\circledR} 2 \mathrm{~F}$ flat sheet (purchased from Membrana Gmbh, $0.2 \mu \mathrm{m}$ nominal pore size). A $25 \mathrm{wt} \%$ IL monomer solution was prepared in methanol with a cross-linker/non-crosslinker molar ratio of $1 / 20$. 2Hydroxy-2-methylpropiophenone (1 wt\% of total monomer weight) was added to the solution as photo-initiator. The membrane was dipped in the solution for a few seconds and taken out before being exposed to UV light (Heraeus TQ 150 lamp with quartz filter, cooled by a water circuit) for $1 \mathrm{~h}$ in air. The distance between the membrane and the quartz filter was $4 \mathrm{~cm}$. After removal from the UV light, the membrane was rinsed thoroughly with ethanol to eliminate surplus IL monomers prior to the metal loading step.

\subsubsection{Metal loading}

The membrane was first soaked in $10 \mathrm{~mL}$ solution of $\mathrm{K}_{2}\left[\mathrm{PdCl}_{4}\right]$ ( $0.05 \mathrm{~mol} / \mathrm{L}$ ) in $\mathrm{H}_{2} \mathrm{O} /$ Methanol (1/1 volume ratio) for $90 \mathrm{~min}$ while shaking on a IKA KS 260 basic shaker at $100 \mathrm{rpm}\left(1.67 \mathrm{~s}^{-1}\right)$. The membrane was then rinsed with ionized water before installation in an Amicon filtration cell with IL-grafted side of the membrane facing up. $10 \mathrm{~mL}$ of $0.5 \mathrm{~mol} / \mathrm{L} \mathrm{NaBH}_{4}$ solution in $\mathrm{H}_{2} \mathrm{O}$ /methanol $(1: 1$ volume ratio, freshly prepared) was then filtered through the membrane (transmembrane pressure $\approx 0.2$ bar). The membrane was then soaked in $\mathrm{NaBH}_{4}$ for one hour before it was rinsed with and kept in deionized water. The membrane was then directly used or cut into appropriate size before use.

\subsection{Permeability test}

Since ethanol is the solvent used for the catalytic reaction, ethanol permeability of the catalytic membrane was measured. The flux measurements were carried out in an Amicon cell at room temperature. The permeability was determined by the slope of the plot of flux density ( $\mathrm{L} \mathrm{min}^{-1} \mathrm{~cm}^{-2}$ ) as a function of transmembrane pressure (bar) (Eq. (1)). The permeability was corrected to $25{ }^{\circ} \mathrm{C}$ by Eq. (2) [19] to take into account the variation of viscosity with temperature. Measurements were repeated twice on each membrane.

$L_{p}=\frac{J_{v}}{\Delta P}$

where $J_{V}$ is the flux density and $\Delta P$ is the transmembrane pressure.

$L_{p}^{25}=L_{p}^{T} \frac{\mu_{T}}{\mu_{25}}=L_{p}^{T} \cdot e^{1708.1(1 / T-1 / 298.15)}$

with $L_{p}^{25}$ as permeability corrected to $25^{\circ} \mathrm{C}, L_{p}^{T}$ as permeability measured at the temperature when the measurement was done, $\mu_{25}$ as ethanol dynamic viscosity at $25^{\circ} \mathrm{C}, \mu_{T}$ as ethanol dynamic viscosity at the temperature when the measurement was done.

\subsection{Preparation of colloidal palladium nanoparticles}

Palladium nanoparticles (PdNPs) were synthesized via thermal decomposition of palladium acetate [20], with the aim of obtaining a catalytic solution to perform the catalytic tests in batch conditions [21-24]. $11.5 \mathrm{mg}(0.05 \mathrm{mmol})$ of $\mathrm{Pd}(\mathrm{OAc})_{2}$ and $113 \mathrm{mg}$ PVP $(10,000 \mathrm{~g} / \mathrm{mol})$ were added in $5 \mathrm{~mL}$ of [MMPIM][NTf $\left.{ }_{2}\right](1,2-$ dimethyl-3-propylimidazolium bis(trifluoromethylsulfonyl)imide) and stirred at room temperature under argon in a Schlenk tube until complete dissolution. The system was then heated and stirred at $100{ }^{\circ} \mathrm{C}$ overnight to give a colloidal system (Scheme 2). PVP acts as a co-stabilizer together with the ionic liquid (molar ratio Pd/PVP monomer $=1 / 20$ ).

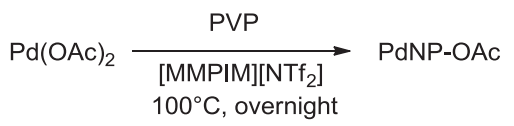

Scheme 2. Synthesis of colloidal palladium nanoparticles.

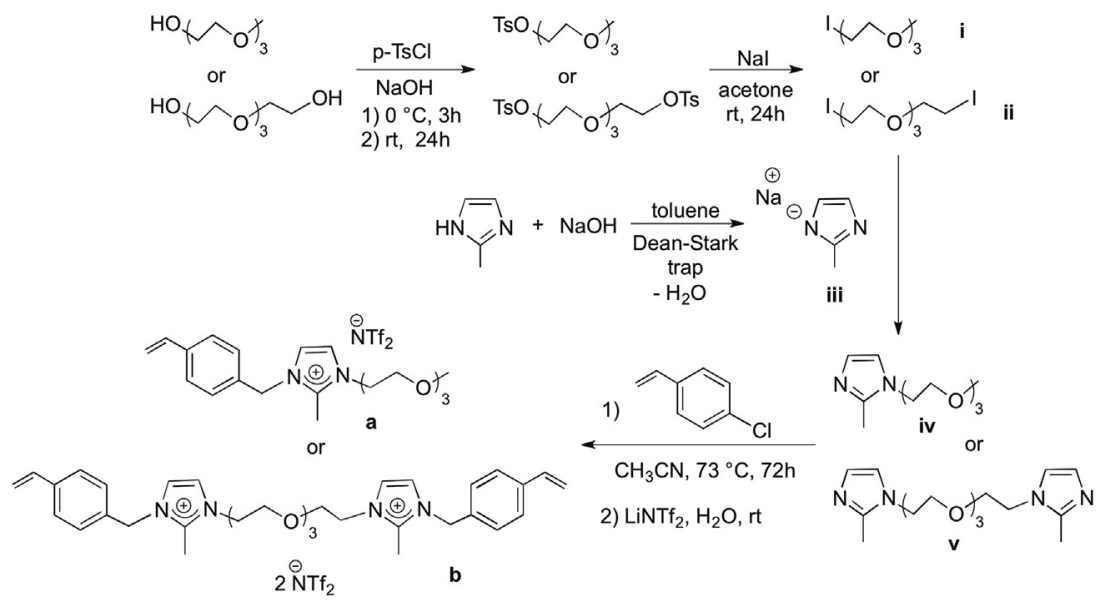

Scheme 1. Synthesis of imidazolium-based derivatives, the monomer a, and the crosslinker $\mathbf{b}$. 


\subsection{Pd-catalyzed Suzuki-Miyaura C-C cross-coupling under batch conditions using a PdNPs-based colloidal catalytic solution}

1-Iodo-4-nitrobenzene (254.1 mg, $1 \mathrm{mmol}$ ), phenylboronic acid (150.8 mg, $1.2 \mathrm{mmol}$ ), KtBuO (286.3 mg, $2.5 \mathrm{mmol}$, in $1 \mathrm{~mL}$ degassed $\mathrm{H}_{2} \mathrm{O}$ ) and PdNP solution ( $1 \mathrm{~mL}, 0.01 \mathrm{mmol} \mathrm{Pd}$ ) were mixed and stirred under argon at the chosen temperature. After the reaction, the reaction mixture was cooled down to room temperature. The organic products were extracted from the catalytic mixture with diethyl ether $(10 \mathrm{~mL} \times 2 \mathrm{~mL})$. The organic phase was filtered over celite. The solvent was then removed by rotary evaporator and the product was analyzed and quantified by ${ }^{1} \mathrm{H}$ NMR and GC-MS analyses using mesitylene as an internal standard.

\subsection{Pd-catalyzed Suzuki-Miyaura C-C cross-coupling under flow- through conditions using a PdNPs-based catalytic membrane}

Catalytic tests were carried out in flow-through reactor configuration. The Amicon cell, equipped with a magnetic stir bar, was placed in a water bath at $60{ }^{\circ} \mathrm{C}$. The reagents were dissolved in 96 vol\% ethanol, stirred and heated in an oil bath at $60{ }^{\circ} \mathrm{C}$ for 20 min before it was poured into the Amicon cell 8050 and filtered through the membrane while stirring. The permeate flow was controlled by a peristaltic pump (Fig. 1). The membrane was then washed by filtering ethanol at the reaction temperature 5 times using the same volume of the reactive solution after each test. The permeate was collected and analyzed by GC-MS and ${ }^{1} \mathrm{H}$ NMR spectroscopy in order to identify the products obtained. Conversion (related with the consumption of the substrate, i.e., 1-iodo-4nitrobenzene) and yield (related to the desired cross-coupling product, i.e., 4-nitrobiohenyl) at the outlet of the catalytic membrane were calculated by two analytical approaches (GC-FID and ${ }^{1} \mathrm{H}$ NMR), using decane and mesitylene, respectively, as internal standards; both methodologies gave similar results. Isolated yields were also determined.

In the case of yield determination, the permeate of the reactive solution together with the washing ethanol was collected. The yield was determined by ${ }^{1} \mathrm{H}$ NMR spectroscopy using mesitylene as an internal standard, which allows measurement of the moles of cross-coupling product produced, taking into account the losses occurring during the extraction steps.

\subsubsection{Catalytic protocol for Suzuki-Miyaura cross-coupling reaction}

The molar ratio $\mathrm{KtBuO} / \mathrm{Ph}-\mathrm{B}(\mathrm{OH})_{2} / 1$-iodo-4-nitrobenzene was 2.5/1.2/1. The stirring speed was $250 \mathrm{rpm}\left(4.17 \mathrm{~s}^{-1}\right)$. The pump permitted to vary the permeate flow rate. The transmembrane pressure was not measured but was in the range of 1-150 mbar as deduced from the solvent permeability. In order to isolate the products, the ethanol present in the permeate was removed via rotary evaporation. The product was then re-dissolved in dichloromethane and washed with water to remove the remaining KtBuO. The water phase was discarded and the organic phase was dried over anhydrous $\mathrm{MgSO}_{4}$ and filtered. Dichloromethane

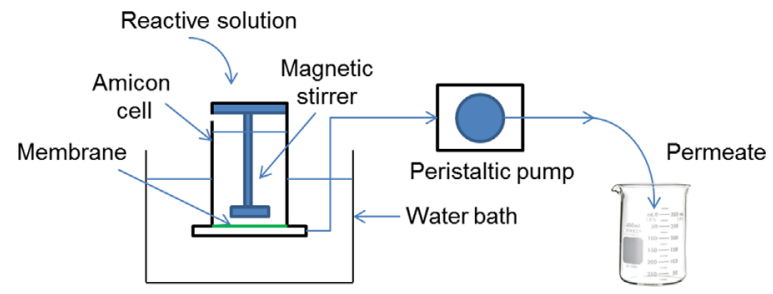

Fig. 1. Experimental set-up for $\mathrm{C}-\mathrm{C}$ cross-coupling reactions performed on the catalytic membrane in a flow-through reactor. was then removed under reduced pressure. The product thus obtained was analyzed by ${ }^{1} \mathrm{H}$ NMR spectroscopy and GC-MS using mesitylene as an internal standard.

\section{Results and discussions}

\subsection{Choice and synthesis of imidazolium-based ionic liquids}

The ionic liquids a and b serve as stabilizers for palladium nanoparticles. The cross-linker $\mathbf{b}$ is used to prevent the dissolution of the poly(ionic liquid) by the organic solvent during the reaction. The length and molecular weight of the cross-linking monomer were appropriately adapted to favor the formation of a homogeneous network [25-28]. The presence of the methyl group at C2 position on the imidazolium ring avoids the formation of molecular palladium $N$-heterocyclic carbene complexes under basic conditions [29], which could eventually promote palladium leaching from the membrane.

As shown in Scheme 1, we prepared first the iodo-ethers $\mathbf{i}$ and ii following a two-step classical methodology where the corresponding alcohols were protected by reaction with $p$-tosyl chloride, giving the corresponding tosylate derivatives; a further nucleophilic substitution using sodium iodide led to $\mathbf{i}$ and $\mathbf{i i}$. These iodo-ethers reacted with the sodium imidazole salt (prepared by deprotonation of imidazole with $\mathrm{NaOH}$ ) to give the neutral monoand bis(imidazole)s iv and $\mathbf{v}$, which were quaternized by treatment with 4-vinylbenzyl chloride. The anion exchange reaction using LiNTf $_{2}$ led to the desired imidazolium derivatives $\mathbf{a}$ and $\mathbf{b}$.

\subsection{Preparation of the catalytic membrane}

In a first step, the IL was photochemically grafted to a PES support membrane. In the second step, the membrane was loaded with palladium via intermatrix synthesis [30]. The IL-grafted membrane was soaked in a solution of $\mathrm{K}_{2}\left[\mathrm{PdCl}_{4}\right]$, where the IL anions $\left(\mathrm{NTf}_{2}^{-}\right)$were exchanged by $\left[\mathrm{PdCl}_{4}\right]^{2-}$.The membrane turned from white color to brown after the ion exchange. Consecutively, a $\mathrm{NaBH}_{4}$ solution was filtered through the membrane, which immediately turned from brown to black from reduction of $\operatorname{Pd}(\mathrm{II})$ to $\operatorname{Pd}(0)$ (Fig. 2).

\subsection{Characterization of the catalytic membrane}

\subsubsection{Degree of grafting}

PES is a photosensitive material which generates radicals under UV irradiation [31]. Consequently, covalent bonds can be formed between the microPES ${ }^{\circledR}$ support membrane and the polyIL during the photografting. The membrane was thoroughly rinsed with ethanol after photo-grafting and ethanol was permitted to evaporate until no more weight change could be observed. This mass was taken as the membrane mass after grafting. The membranes were weighed before and after the photografting step (Section 2.2.1) to determine the amount of ionic liquid grafted onto the PES membrane. The grafting degree was calculated by Eq. (3).

Grafting degree $=\frac{\left(m_{g}-m_{i}\right)}{m_{i}}$

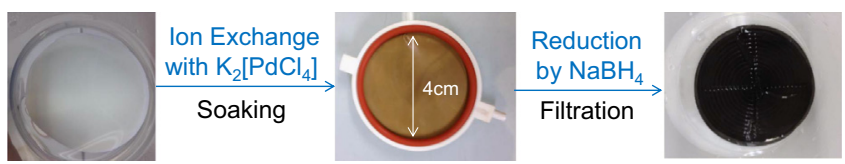

Fig. 2. Palladium loading via intermatrix synthesis. 
where $m_{g}$ is the membrane weight after photo-grafting (Section 2.2.1) and $m_{i}$ is the membrane weight before photo-grafting.

The average degree of grafting was found to be $32.0 \%$ with standard deviation of $2.2 \%$. The average mass of poly(ionic liquid) grafted onto the membrane was $1.2 \mathrm{mg} / \mathrm{cm}^{2}$.

\subsubsection{Ethanol permeability of the catalytic membrane}

The average ethanol (96 vol\% ) permeability of the catalytic membrane at $25^{\circ} \mathrm{C}$ was $15 \pm 2 \mathrm{~mL} /\left(\mathrm{min} \mathrm{cm}^{2}\right.$ bar $)$, which is comparable to the PES virgin membrane permeability $(17.9 \mathrm{~mL} /(\mathrm{min}$ $\mathrm{cm}^{2}$ bar)). No significant drop in the permeability (or pore size reduction) of the membrane was triggered by the grafting.

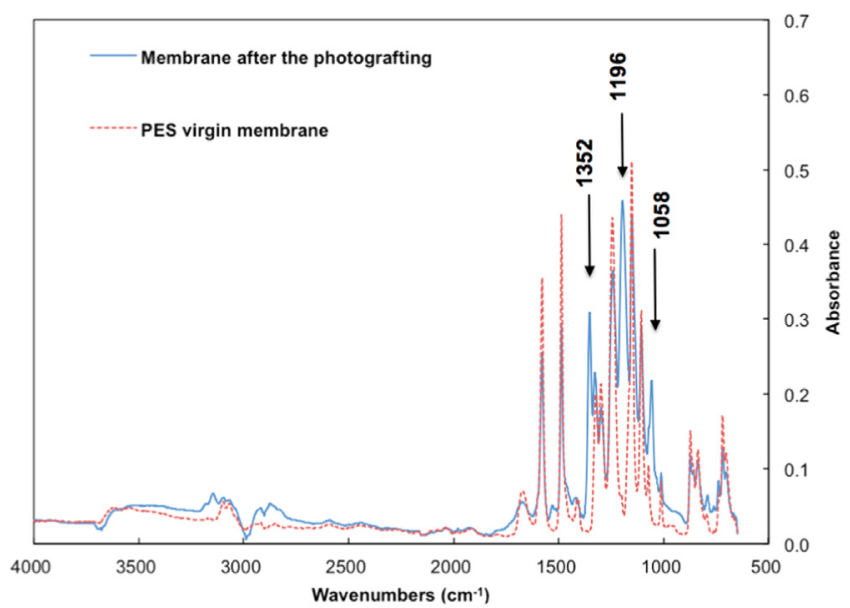

Fig. 3. ATR-IR spectra of pristine PES membrane (dotted red line) and the photografted membrane (solid blue line). (For interpretation of the references to color in this figure legend, the reader is referred to the web version of this article.)

\subsubsection{SEM and ATR-IR analyses}

The IL-grafted membrane was analyzed by ATR-IR and SEM. Both analyses indicated that the membrane surface was modified by the ionic liquid.

Change of the chemical composition on the membrane surface was confirmed by ATR-IR analysis. Fig. 3 shows the appearance of new absorption bands for the grafted membrane. The absorption bands below $1500 \mathrm{~cm}^{-1}$ are mainly assigned to the vibrations of bis(trifluoromethylsulfonyl)imide anion: $1352 \mathrm{~cm}^{-1}$ associated with the $\mathrm{SO}_{2}$ asymmetric stretching; $1196 \mathrm{~cm}^{-1}$ is assigned to the $\mathrm{CF}_{3}$ asymmetric stretching. The absorption band at $1058 \mathrm{~cm}^{-1}$ can be attributed to the SNS asymmetric stretching, a ring in-plane asymmetric stretching and a $\mathrm{C}-\mathrm{C}$ stretching [32]. These characteristic bands evidence the coverage of the membrane surface with the ionic liquids involved.

SEM images corroborated the chemical modification of the membrane after the photo-grafting treatment by an obvious morphology change. (Fig. S1 in the Supplementary information).

\subsubsection{Palladium loading and distribution inside the membrane}

The average palladium loading of the catalytic membrane $(4 \mathrm{~cm}$ of diameter) was $(7.5 \pm 0.4) \times 10^{-3} \mathrm{mmol}$, or $(0.60 \pm 0.03) \times$ $10^{-3} \mathrm{mmol} / \mathrm{cm}^{2}$ (normalized to the membrane surface area) and $0.5210^{-3} \mathrm{mmol} / \mathrm{mg}$, normalized to mass of polylL. By comparing the quantity of the $\mathrm{NTf}_{2}$ anion coming from the IL grafted onto the membrane and the final palladium loading, we can inferred that ca. $60 \%$ of the $\mathrm{NTf}_{2}$ anion was exchanged by $\left[\mathrm{PdCl}_{4}\right]^{2-}$.

Ethanol was filtered through the catalytic membrane to study the possible palladium leaching from the membrane. By ICP-OES analyses, no leaching was observed (in the permeate, the palladium concentration was below the detection limit of the technique, i.e., 3 and $15 \mathrm{ppb}$ respectively for the detecting wavelength of $340.3 \mathrm{~nm}$ and $361.0 \mathrm{~nm}$ (see the Supplementary information for details).

a

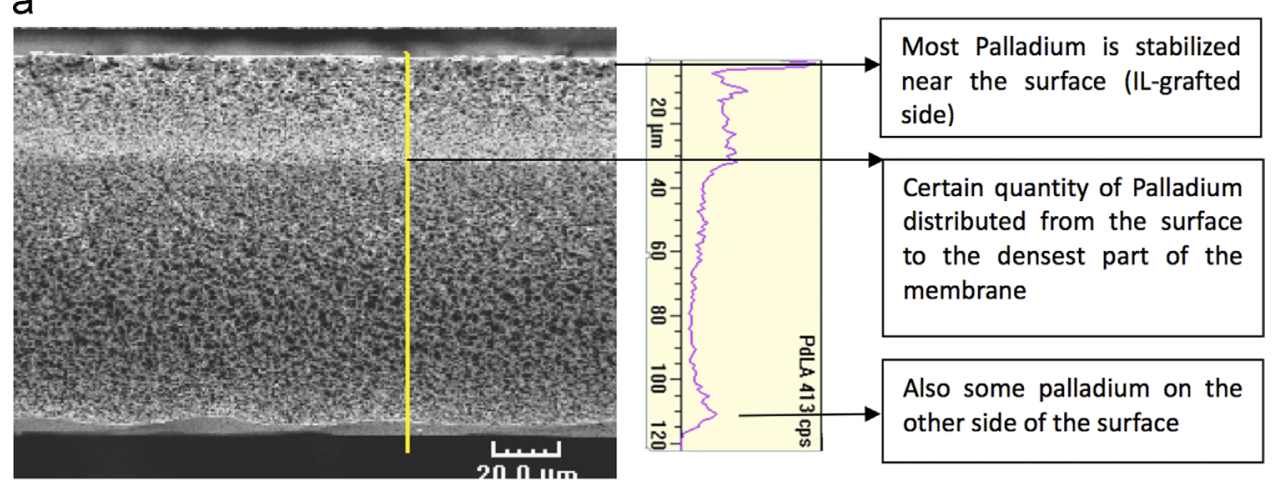

b

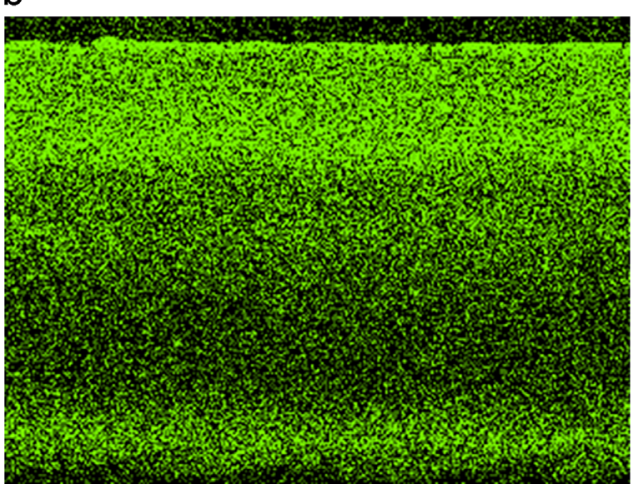

Fig. 4. SEM-EDX analysis: palladium distribution along the membrane thickness (a) and palladium cartography (b). 
The PES flat sheet membrane is an asymmetric membrane, with the smallest pore sizes localized approximately $30-40 \mu \mathrm{m}$ from the IL-grafted membrane surface. The IL-grafted membrane surface was the side of the membrane facing the UV light during the photografting. Consequently, most of the ionic liquid was grafted to the part of the membrane facing the light near the surface. EDX SEM analysis provided us information about the palladium concentration along the membrane thickness. As shown in Fig. 4, most palladium was essentially distributed from the IL-grafted surface to the densest part of the membrane.

TEM analyses of the catalytic membrane's cross-section with zooming on the IL-modified side showed that most palladium NPs were stabilized by the poly(ionic liquid) rather than by the PES support membrane (see Fig. S2 in the Supplementary information). PdNPs (mean diameter: $2 \pm 1 \mathrm{~nm}$; see Fig. 7a inside the membrane were very close to each other (inter-NP distance in the same order as the NP size). The large number of PdNPs per unit volume (ca. $4 \times 10^{14} \mathrm{~mm}^{-3}$, this value is deduced from the palladium concentrated zone (i.e. reactive zone) of the membrane see Fig. S2 in Supplementary information) and the small inter-particle distance help to intensify the contact between reactants and catalyst by reducing the diffusion length but could induced concentration gradient inside the PIL containing PdNPs.

Our group previously published a work on catalytic hollow fiber membranes obtained using acrylic acid as modifying agent instead of ionic liquid [33]. The PdNP mean diameter was found to be $5 \pm 2 \mathrm{~nm}$ in the case of poly(acrylic acid) (polyAA). The difference in palladium size may result from the fact that the main chain of polyAA is negatively charged while that of polyIL is positively charged. The affinity of the palladium precursors towards the grafting layer was also different.

EDX TEM analysis provided information of elemental composition at different zones of the membrane (Fig. S3 in Supplementary information). Contents of $\mathrm{S}, \mathrm{N}$ and Pd represent the PES support membrane, ionic liquid polymer and PdNPs, respectively (sulfur is also present in the anion of polyIL, but its quantity is estimated to be less than $10 \%$ of total sulfur). These analyses showed that palladium loading increases with the N/S ratio (Fig. S4 in Supplementary information), confirming the fact that palladium NPs are stabilized by polyIL rather than the PES support membrane, which is consistent with the TEM images (Fig. S2 in Supplementary information).

\subsection{Comparison to non-grafted PES membrane loaded with palladium}

A PES virgin membrane was loaded with palladium in the same manner as described above (Section 2.2.2). The membrane color was slightly tinged with pale gray after the metal loading. The palladium loading of the PES virgin membrane was $3.4 \cdot 10^{-5} \mathrm{mmol} \mathrm{cm}^{-2}, 17$ times less than that of IL modified membrane. Unlike the IL functionalized membrane, PdNPs present in the PES virgin membrane were mostly aggregated, as shown in Fig. 5. The presence of PdNPs inside the non-modified PES membrane was probably due to the adsorption of the palladium salt on the membrane surface or to the encapsulation of the $\mathrm{K}_{2}\left[\mathrm{PdCl}_{4}\right]$ solution inside the membrane pores by capillary forces.

\subsection{Catalytic study}

\subsubsection{Catalytic performance of the palladium colloidal system}

For the preparation of colloidal PdNPs (see Section 2.4), [MMPIM] $\left[\mathrm{NTf}_{2}\right]$ was used as solvent instead of monomer a to avoid the polymerization of monomer a at relative high temperature [34]. PVP was used as the co-stabilizer for the corresponding PdNPs. This colloidal catalytic system was tested under batch conditions in order to compare its performance with that of the catalytic membrane.

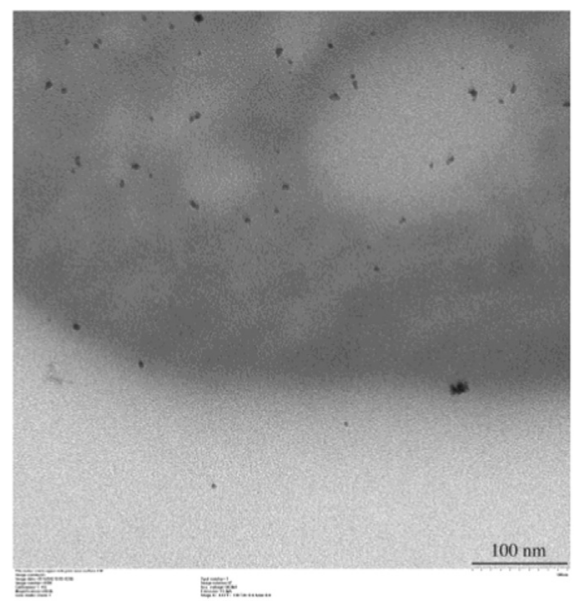

Fig. 5. Non-modified PES membrane loaded with palladium.

TEM analysis showed homogeneously dispersed PdNPs in ionic liquid with few agglomerates (Fig. 6a). The mean diameter of the PdNPs was $4 \pm 2 \mathrm{~nm}$, about twice the size of those immobilized in the membrane (see above). For bigger particles, a lower reactivity is then expected, because the decrease of both the relative number of palladium atoms at the metallic surface and the atoms on edges and corners of the nanoclusters, showing low coordination numbers (related with their reactivity). In addition, despite the presence of the co-stabilizer (PVP), agglomerates could not be completely avoided (Fig. 6b). Light scattering measurements evidenced the presence of particles larger than $100 \mathrm{~nm}$.

Stokes number is a dimensionless value defined as the ratio of the characteristic time of a particle to a characteristic time of the flow (Eq. (4)). When Stk «1, particles follow streamlines closely.

$S t k=\frac{\rho d^{2} N}{18 \mu}$

with $\rho$ and $d$ as respectively the density $\left(12.0 \times 10^{3} \mathrm{~kg} \mathrm{~m}^{-3}\right)$ and diameter $\left(4 \times 10^{-9} \mathrm{~m}\right)$ of PdNPs, $N$ as agitator speed $\left(8.3 \mathrm{~s}^{-1}\right)$ and $\mu$ as dynamic viscosity of [MMPIM] $\left[\mathrm{NTf}_{2}\right]\left(\approx 20 \times 10^{-3} \mathrm{k} \mathrm{gm}^{-1} \mathrm{~s}^{-1}\right.$ $[35,36])$. The Stokes number of the colloidal system was calculated to be $5 \cdot 10^{-12}$, indicating that the PdNPs follow the streamline so closely that the relative velocity between PdNPs and the liquid phase is nearly zero. The convection is inefficient and actually negligible. The mass transfer is therefore effectuated uniquely by diffusion. This boundary layer will increase with the consumption of the reactants near the catalyst surface to reach a constant value after few second corresponding to a Sherwood number equal to 2 [37,38]. For our particles, the boundary layer thickness is only $2 \mathrm{~nm}$ indicating that the mass transfer coefficient will be high.

Compared to the catalytic membrane, around 200 times fewer PdNPs per unit volume are present in the colloidal system. The mean inter-particle distance calculated from the Pd concentration and the particle diameter is in the range of $50-100 \mathrm{~nm}$, larger than those observed in the catalytic membrane.

The Pd-based colloidal system was applied in the Suzuki-Miyaura cross-coupling between 1-iodo-4-nitrobenzene and phenylboronic acid, which was chosen as benchmark reaction (Scheme 3 ) at three different temperatures $\left(60^{\circ} \mathrm{C}, 80^{\circ} \mathrm{C}\right.$ and $\left.120^{\circ} \mathrm{C}\right)$. Results are summarized in Table 1. The PdNP colloidal system was active, giving mainly the expected cross-coupling product, up to 93\% working at low temperature (entry 1 ). Whatever the temperature was, ca. $10 \%$ biphenyl (i.e., the homo-coupling byproduct coming from phenylboronic acid) was formed under batch conditions.

At $60{ }^{\circ} \mathrm{C}$, we followed the kinetics of the reaction by taking samples at different reaction times. By plotting $\operatorname{Ln}\left(C / C_{0}\right)$ as a function of time, we got a linear correlation (with $C$ as reactant concentration 
a

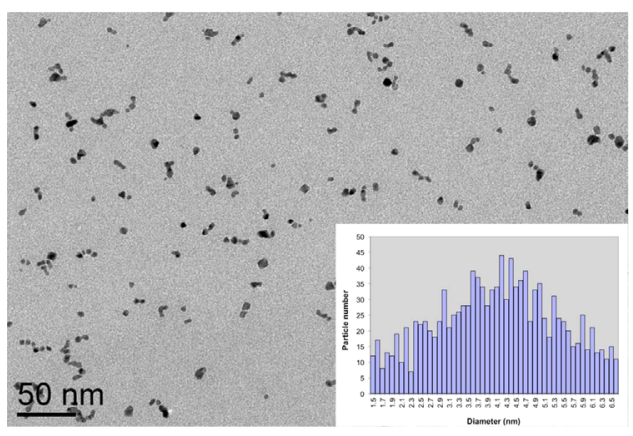

b

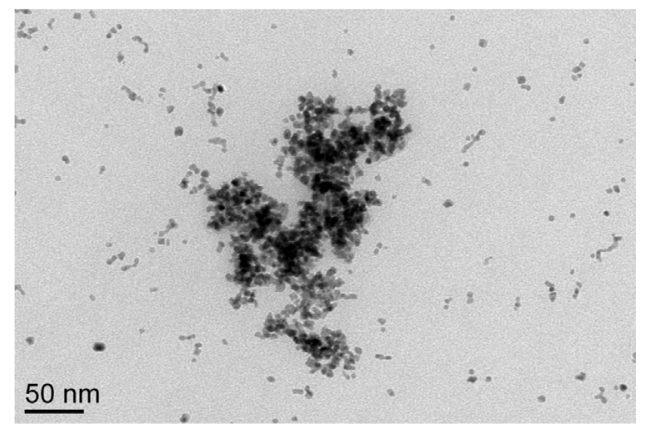

Fig. 6. TEM images of the PdNPs in the colloidal system and its size distribution (1389 particles measured).

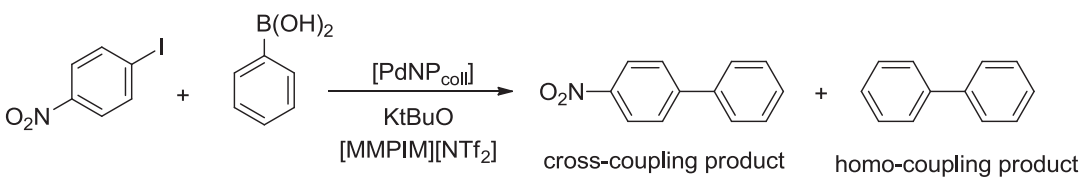

Scheme 3. The Suzuki-Miyaura cross-coupling reaction under batch conditions catalyzed by colloidal PdNPs.

Table 1

Pd-catalyzed Suzuki-Miyaura cross-coupling reaction at different temperatures using the preformed colloidal system (see Scheme 3). ${ }^{\text {a. }}$

\begin{tabular}{lllll}
\hline Entry & $\begin{array}{l}T \\
\left({ }^{\circ} \mathrm{C}\right)\end{array}$ & $\begin{array}{l}\text { Reaction } \\
\text { time }(\mathrm{h})\end{array}$ & $\begin{array}{l}\text { Conversion } \\
(\%)^{\mathrm{b}}\end{array}$ & $\begin{array}{l}\text { Selectivity towards the cross-coupling } \\
\text { product }(\%)^{\mathrm{b}}\end{array}$ \\
\hline 1 & 60 & 4 & 96 & 93 \\
2 & 80 & 5.3 & 100 & 87 \\
3 & 120 & 1 & 100 & 92
\end{tabular}

a Reaction conditions: molar ratio: 1-iodo-4-nitrobenzene/phenylboronic acid/ $\mathrm{KtBuO} / \mathrm{Pd}=1 / 1.2 / 2.5 / 0.01$; in IL [MMPIM][NTf2] ( $1 \mathrm{~mL})$.

${ }^{\mathrm{b}}$ Determined by GC and ${ }^{1} \mathrm{H}$ NMR using mesitylene as internal standard.

at time $t$ and $C_{0}$ as its initial concentration). Therefore, the apparent kinetics for the colloidal system in the batch reactor turned out to be a first order reaction with the apparent reaction rate constant determined as $k_{\text {app, batch }}=2.3 \times 10^{-4} \mathrm{~s}^{-1}$, or $0.22 \mathrm{~s}^{-1} \mathrm{~g}^{-1}$ when normalized to mass of palladium and $6 \times 10^{-4} \mathrm{~s}^{-1} \mathrm{~m}^{2}$, when normalized to total catalyst surface area (The PdNP were considered as cuboctahedron clusters for the surface calculation [39]).

\subsubsection{Catalytic performance of the membrane}

For a catalytic membrane, the reaction time can be expressed as the residence time of the solution inside the membrane (Eq. (5)):

$\tau=\frac{L}{F} \cdot \varepsilon \cdot S=\varepsilon \cdot \frac{L}{J}$

where $L$ is the membrane thickness $(\mathrm{cm}), F$ the permeate flow rate $(\mathrm{mL} / \mathrm{s}), S$ the membrane surface area $\left(\mathrm{cm}^{2}\right)$ and $J$ the flux density $\left(\mathrm{mL} /\left(\mathrm{s} \mathrm{cm}^{2}\right)\right)$. The membrane thickness $L$ is shown on Fig. 4 and equal to $110 \mu \mathrm{m}$. The membrane surface area is $12.6 \mathrm{~cm}^{2}$. The porosity $\varepsilon$ is unknown and therefore taken to 1 for the following residence time calculations. The resulting reaction times do not take into account of the membrane porosity which is probably in the range of $0.7-0.8$ for this kind of membrane. The real reaction time is thus $0.7-0.8$ times smaller than the reaction time reported here.

The benchmark Pd-catalyzed cross-coupling reaction was carried out in ethanol at $60^{\circ} \mathrm{C}$ using the catalytic membrane under flow-through conditions (Scheme 4). Results are shown in Table 2. Full conversions were achieved by one single filtration with a residence time of ca. $9 \mathrm{~s}$. No homo-coupling byproducts were observed. Given the selectivity observed in the batch reactor, the

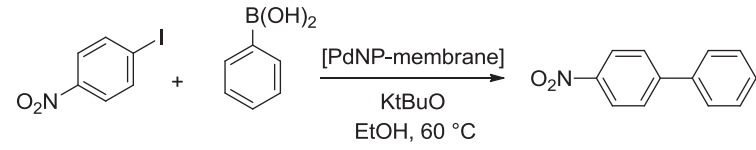

Scheme 4. Pd-catalyzed Suzuki-Miyaura cross-coupling under flow-through conditions.

Table 2

Suzuki-Miyaura cross-coupling reaction catalyzed by the catalytic membrane at different conditions (see Scheme 4). ${ }^{\mathrm{a}}$.

\begin{tabular}{lllllll}
\hline $\begin{array}{l}{[\mathrm{C}]} \\
(\mathrm{mol} / \\
\mathrm{L})^{\mathrm{b}}\end{array}$ & $\begin{array}{l}\text { Flow rate } \\
(\mathrm{mL} / \mathrm{min})\end{array}$ & $\begin{array}{l}\text { Filtration } \\
\text { volume } \\
(\mathrm{mL})\end{array}$ & $\begin{array}{l}\text { Pd/substrate } \\
\text { molar ratio }\end{array}$ & $\begin{array}{l}\tau^{\mathrm{c}} \\
(\mathrm{s})\end{array}$ & $\begin{array}{l}\text { Conversion } \\
(\%)^{\mathrm{d}}\end{array}$ & $\begin{array}{l}\text { Selectivity } \\
(\%)^{\mathrm{d}}\end{array}$ \\
\hline \multirow{2}{*}{0.016} & 1.38 & 62 & $1 / 132$ & 5.8 & 83.4 & 100 \\
& 0.88 & & & 9.1 & 100 & 100 \\
0.032 & 0.88 & 31 & & 9.1 & 100 & 100 \\
\hline
\end{tabular}

a Reaction conditions: molar ratio 1-iodo-4-nitrobenzene/phenyl boronic acid/ $\mathrm{KtBuO} / \mathrm{Pd}=1 / 1.2 / 2.5 / 0.007$.

b Concentration of 1-iodo-4-nitrobenzene.

${ }^{\mathrm{c}}$ Residence time.

${ }^{\mathrm{d}}$ Determined by GC and ${ }^{1} \mathrm{H}$ NMR using mesitylene as internal standard.

formation of biphenyl should be much slower than that corresponding to the cross-coupling product formation. In the case of the catalytic membrane, the residence time of reagents in the membrane was so short that the formation of the homo-coupling byproduct was prevented. Actually, the high reactivity of the catalytic membrane favors the chemoselectivity of the process. Interests on catalytic membranes have recently aroused [40,41] but the reaction times of those membranes for Suzuki coupling reactions are in the order of hours and catalyst leaching is produced. Our catalytic membrane herein reported is so efficient that the reaction is complete within seconds.

The isolated yield obtained was $82 \%$ for a residence time of $9.1 \mathrm{~s}$. The catalytic membrane was re-used 8 times without activity loss (no more runs were done), showing the robustness of the membrane. TEM analysis after catalytic membrane reusing did not evidence significant changes in the shape and size of the PdNPs (Fig. 7). Actually, a slight increase of the NP diameter occurs but, taking into account the standard deviation, the NP diameter remains practically constant. Neither palladium nor IL was detected in the 
a

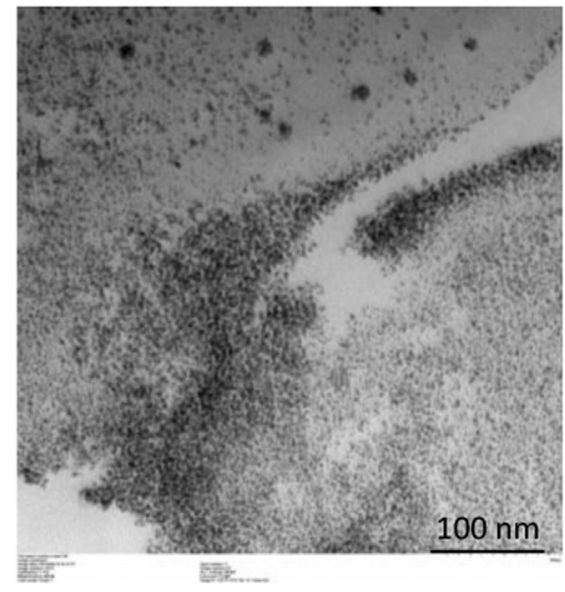

b

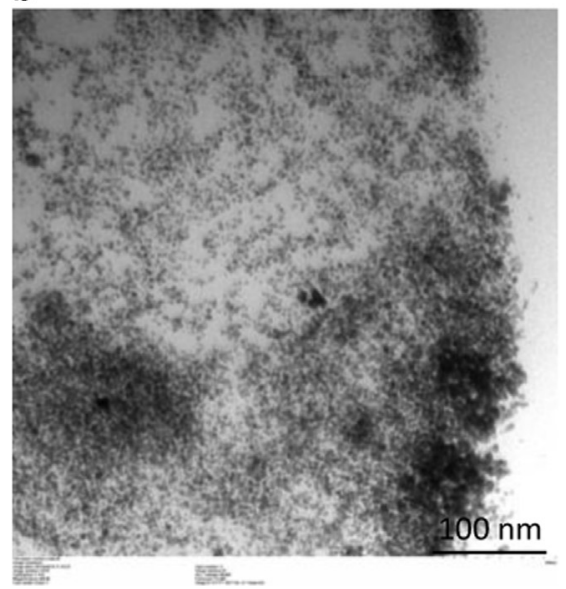

Fig. 7. TEM images of the catalytic membrane: (a) before and (b) after the 9th catalytic run, showing the corresponding PdNP mean diameter.

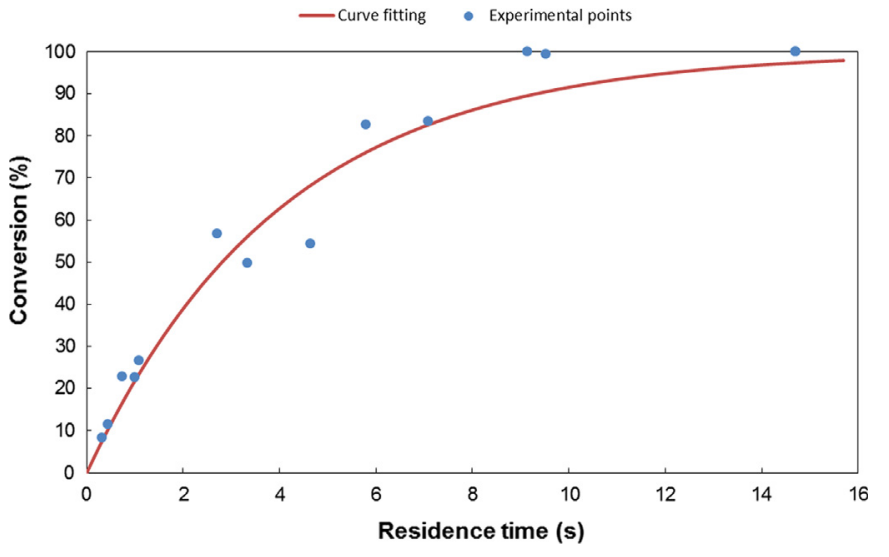

Fig. 8. Conversion as a function of residence time.

product, which proved membrane stability under catalytic conditions and filtration flows.

The reaction was then tested at different flow rates at $60{ }^{\circ} \mathrm{C}$ at 1-iodo-4-nitrobenzene concentration of $0.016 \mathrm{~mol} / \mathrm{L}$. Conversion increased with residence time as shown in Fig. 8.

$T=60{ }^{\circ} \mathrm{C}$, [1-iodo-4-nitrobenzene $]=0.016 \mathrm{~mol} \mathrm{~L}^{-1}$, Permeate flux density: $27-1300 \mathrm{~L} \mathrm{~h}^{-1} \mathrm{~m}^{-2}$; data points at $100 \%$ conversion not taken into account for curve fitting.

Nagy established monodimensional complete models of pseudo-homogenous catalytic membrane reactors that allow the prediction of conversion from the physico-chemical parameters, the kinetic constant and the flux density [5]. These models take into account the diffusion and convection mass transfer in the boundary layers above the membrane and inside the membrane (in relation to the reaction) containing the catalytic NP. As the diffusion is a slow process compared to the convection, the Peclet parameter $(\mathrm{Pe})$ is used to describe which mechanism is dominant in each part of the catalytic membrane (Eq. (6)).

$$
P e=\frac{v \cdot \delta}{D}
$$

where $\nu$ is the fluid velocity, $\delta$ the thickness of the boundary layer or membrane thickness, and $D$ the diffusion constant. Nagy indicates the diffusion flux can be considered negligible compared to convective flux when Pe is larger than 3.

Under our experimental conditions, the $P e$ of the boundary layer increases from 3.4 to 166 and from 2 to 97 in the catalytic membrane when the flux density rises from 27 to $1300 \mathrm{~L} \mathrm{~h}^{-1} \mathrm{~m}^{-2}$.
The diffusion can be neglected at high flux density and have a small influence at low flux density (i.e. high conversion or longer residence time). In contrast to the colloidal system, convective mass transfer becomes dominant in mass transfer for the catalytic membrane. The relative velocity between the fluid and the catalyst equals to the fluid velocity as the catalyst is immobilized inside the membrane.

Isothermal plug flow is achieved in the membrane pores under the experimental conditions [42-45]. Hence a first order pseudohomogeneous reaction is assumed in a first approach to model the catalytic membrane. Taking into account only the convection and reaction inside the membrane, the differential mass balance can be written as Eq. (7) and solved as Eq. (8) [46]. Then the conversion can be simply expressed as Eq. (9):

$v \frac{d c}{d z}+k_{\text {papp }, \text { memb }} c=0$

$\operatorname{Ln} \frac{c}{c_{0}}=-k_{\text {papp }, \operatorname{memb}} \cdot \frac{L}{v}$

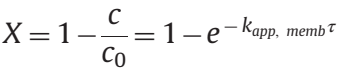

where $c_{0}$ is the initial reactant concentration; $X$ is the conversion; $k_{\text {app , memb }}$ the apparent reaction constant; and $\tau$ the residence time inside the membrane. It should be noted that this apparent reaction constant is not the true kinetics constant of the reaction. In addition, it disregards the diffusion step towards the catalyst inside the polyIL containing the nanoparticules and the membrane structure which could induce a preferential pathway.

The apparent reaction constant for the membrane was deduced through fitting of Eq. (9) to experimental points (Fig. 8), found to be $0.25 \mathrm{~s}^{-1}$ or $309.62 \mathrm{~s}^{-1} \mathrm{~g}^{-1}$ when normalized to palladium mass, and $0.4 \mathrm{~s}^{-1} \mathrm{~m}^{-2}$ when normalized to palladium surface area (PdNPs considered as cuboctahedron clusters for the surface calculation [39]).

The data points at $100 \%$ conversion (low flux density) were not taken into consideration for curve fitting because diffusion can have an influence on mass transfer. It is worth mentioning that, different from Nagy's model, our catalytic membrane is not homogeneous, exhibiting a concentration gradient of PdNPs (see above Fig. 4), which can lead to a reactivity gradient. The deviation between the experimental data and calculated fitting can partly be attributed to the heterogeneous distribution of PdNPs inside the membrane. Comparing with the results under batch conditions $\left(k_{\text {app, batch }}=0.22 \mathrm{~s}^{-1} \mathrm{~g}^{-1}\right)$, the catalytic membrane triggered an acceleration of the reaction by three orders of magnitude. 


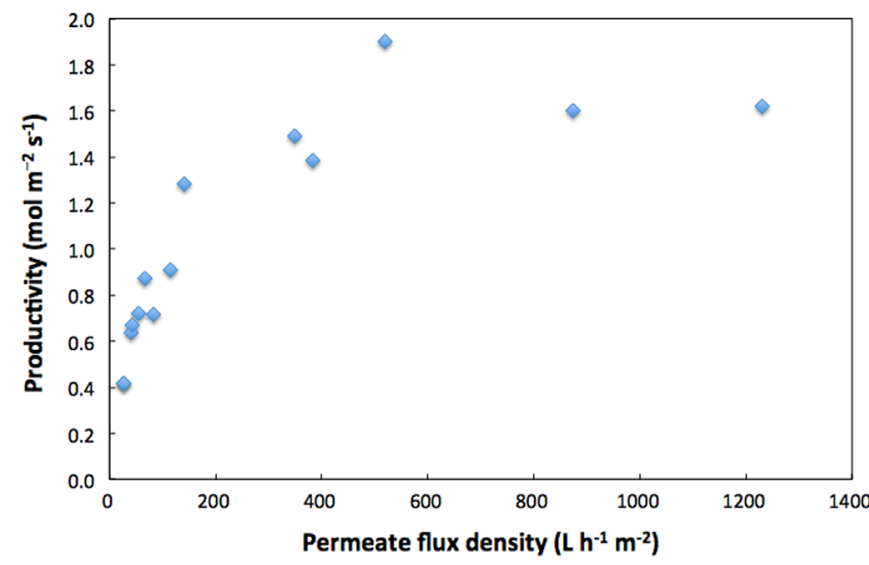

Fig. 9. Productivity per square meter of membrane as a function of permeate flux density. See Fig. 8 for experimental conditions.

In Fig. 9, the productivity per square meter of membrane is plotted versus the permeate flux density. The mass transfer is more effective at higher flow rates where the convection process dominates. Experimental results showed that the membrane offers a higher productivity at a higher flow rate before reaching a maximum plateau, because of the more effective mass transfer (Fig. 9). At low flow rates, the conversion was complete while the productivity was low. When the flow rate increased, the productivity increased and reached its maximum whereas the conversion decreased (Fig. 8). Once the maximum productivity was achieved, the reaction was no more limited by the mass transfer of reactants in the membrane pores, and accordingly the conversion decrease was limited by reactivity (due to the short residence time). Rubinstein show theoretically that when molecule diameter is smaller than the polymer correlation length (average distance from a monomer on one chain to the nearest monomer on another chain), the molecule diffusion coefficient (determined from the Soke Einstein equation) is mainly determined by the solvent viscosity and not strongly affected by polymers [47]. Since swelling of polyIL in ethanol was observed, the reactant diffusion inside the polyIL should not be a limiting step at high flow rates.

The membrane can continuously be treated at $60{ }^{\circ} \mathrm{C}$ under a flow of ca. $1.3 \mathrm{~mol} \mathrm{~h}^{-1} \mathrm{~m}^{-2}$ of 1-iodo-4-nitrobenzene at $100 \%$ conversion. Besides the acceleration of the reaction, another advantage of the catalytic-based membrane reactors working under flow-through conditions is that they offer a more compact production unit compared to traditional batch reactors, especially in the configuration of hollow fibers. Assuming that the catalytic performance remains when the catalytic membrane is prepared as a hollow fiber and that hollow fiber specific surface (corresponding to a conventional hollow fiber module) is $1000 \mathrm{~m}^{2} / \mathrm{m}^{3}$, then a production capacity of ca. $1300 \mathrm{~mol} \mathrm{~h}^{-1} \mathrm{~m}^{-3}$ (ca. $260 \mathrm{~kg} \mathrm{~h}^{-1} \mathrm{~m}^{-3}$ ) can be achieved for hollow fiber modules.

By immobilizing PdNPs inside the porous polymer matrix, the catalytic membrane succeeds in accelerating the Suzuki-Miyaura cross-coupling reaction. Exerting a higher flow rate helps to improve the reactant mass transfer toward the catalytic nanoparticles which are concentrated inside a polymeric gel. PdNPs inside the reactive zone of the catalytic membrane are smaller and much (200 times) more concentrated than in the colloidal system. The replacement of viscous ionic liquid by ethanol as solvent for the reaction also increases the diffusion coefficient to a large extent (ca. 34 times $[35,36])$. All these factors together lead to a better catalytic performance of the catalytic membrane in comparison to the colloidal system.

\section{Conclusions}

In summary, we prepared an efficient catalytic membrane using microPES ${ }^{\mathbb{R}}$ membrane as support and imidazolium-based ionic liquids as modifying agents. The average diameter of the PdNPs stabilized by the polyIL inside the catalytic membrane was ca. $2 \mathrm{~nm}$. No leaching of palladium from the membrane was observed, neither during filtrations nor in the course of the catalytic reaction.

The catalytic membrane showed remarkable catalytic performance on $\mathrm{C}-\mathrm{C}$ cross-coupling. The membrane was so active that with a residence time of some seconds, the conversion was complete, without formation of byproducts. The desired product was directly and continuously obtained in the permeate once the reaction started. No separation of the catalyst from the product was required. The high efficiency of the catalytic membrane favored a better chemoselectivity towards the kinetically favored product, achieving full conversion under mild conditions.

The catalytic membrane succeeded in greatly accelerating ( $\approx 2000$ times in terms of reaction time for total conversion) the Suzuki-Miyaura cross-coupling reaction compared to the colloidal PdNPs under batch conditions, due to the combination of several effects: smaller nanoparticles and higher catalyst concentration, use of low viscosity swelling solvent, and improved the mass transfer phenomenon. The catalytic membrane gave high productivity at high flow rates. Consequently, the membrane is probably more interesting for diffusion controlled reactions (i.e. fast intrinsic reaction). For kinetic-limited reactions, the acceleration of the process by the membrane may be less significant but significant due to the high PdNP concentration.

Studies concerning the catalytic membrane applications in the synthesis of compounds with added value in fine chemistry are underway.

\section{Acknowledgments}

The authors gratefully acknowledge the French Ministry of Education and Research, Paul Sabatier University and the National Center for Scientific Research (CNRS) for financial support and funding a scholarship to Y. Gu through the FOAM2 project (Paul Sabatier University).

\section{Appendix A. Supporting information}

Supplementary data associated with this article can be found in the online version at http://dx.doi.org/10.1016/j.memsci.2015.05.051.

\section{References}

[1] T. Westermann, T. Melin, Flow-through catalytic membrane reactors-principles and applications, Chem. Eng. Process. Process Intensif 48 (2009) 17-28.

[2] M.M. Pendergast, E.M.V. Hoek, A review of water treatment membrane nanotechnologies, Energy Environ. Sci. 4 (2011) 1946-1971.

[3] J.N. Armor, Applications of catalytic inorganic membrane reactors to refinery products, J. Membr. Sci. 147 (1998) 217-233.

[4] S. Heng, Catalytic Membrane Reactor for Water and Wastewater Treatment, Hong Kong University of Science and Technology, Hong Kong, 2006.

[5] E. Nagy, Diffusive plus convective mass transport through catalytic membrane layer with dispersed nanometer-sized catalyst, Int. J. Compos. Mater. 2 (2012) 79-91.

[6] A. Julbe, D. Farrusseng, C. Guizard, Porous ceramic membranes for catalytic reactors-overview and new ideas, J. Membr. Sci. 181 (2001) 3-20.

[7] J.N. Armor, Membrane catalysis: where is it now, what needs to be done? Catal. Today 25 (1995) 199-207.

[8] J.A.M.F. Kapteijn, J. Weitkamp, J.-A. Dalmon, Catalytic Membrane Reactors, in: H.K.G. Ertl, J. Weitkamp (Eds.), Handbook of Heterogeneous Catalysis, VCH, Weinheim, Germany, 1997, p. 1387. 
[9] G. Saracco, H. Neomagus, G.F. Versteeg, W.P.M. Van Swaaij, High-temperature membrane reactors: potential and problems, Chem. Eng. Sci. 54 (1999) 1997-2017.

[10] L. Paturzo, A. Basile, E. Drioli, High temperature membrane reactors and integrated membrane operations, Rev. Chem. Eng. 18 (2002) 511-552.

[11] D. Astruc, Nanoparticles and Catalysis, WILEY-VCH, 2008, ISBN: 9783527621323, http://dx.doi.org/10.1002/9783527621323.

[12] S. Papp, R. Patakfalvi, I. Dékány, Formation and stabilization of noble meta nanoparticles, Croat. Chem. Acta 80 (2007) 493-502.

[13] J. Hang, L. Shi, X. Feng, L. Xiao, Electrostatic and electrosteric stabilization of aqueous suspensions of barite nanoparticles, Powder Technol. 192 (2009) $166-170$.

[14] C. Janiak, Ionic liquids for the synthesis and stablization of nanoparticles, Z Naturforsch 68 (2013) 1059-1089.

[15] S. Nath, S. Jana, M. Pradhan, T. Pal, Ligand-stabilized metal nanoparticles in organic solvent, J. Coll. Interface Sci. 341 (2010) 333-352.

[16] H. Hagiwara, Y. Sugawara, K. Isobe, T. Hoshi, T. Suzuki, Immobilization of Pd (OAc) 2 in ionic liquid on silica: application to sustainable Mizoroki-Heck reaction, Org. Lett. 6 (2004) 2325-2328.

[17] Y.M.A. Yamada, T. Watanabe, T. Beppu, N. Fukuyama, K. Torii, Y. Uozumi, Palladium membrane-installed microchannel devices for instantaneous Suzuki-Miyaura cross-coupling, Chem. - Eur. J. 16 (2010) 11311-11319.

[18] T.K. Carlisle, G.D. Nicodemus, D.L. Gin, R.D. Noble, CO2/light gas separation performance of cross-linked poly(vinylimidazolium) gel membranes as function of ionic liquid loading and cross-linker content, J. Membr. Sci. 397398 (2012) 24-37.

[19] S.K.P.M.J. Assael, Measurements of the viscosity of alcohols in the temperature range 290-340 K at pressures up to $30 \mathrm{MPa}$, Int. J. Thermophys. 15 (1994) 95-107.

[20] P.K. Gallagher, M.E. Gross, The thermal decomposition of palladium acetate, J. Therm. Anal. Calorim. 31 (1986) 1231-1241.

[21] F. Fernández, B. Cordero, J. Durand, G. Muller, F. Malbosc, Y. Kihn, E. Teuma, M. Gómez, Palladium catalyzed Suzuki C-C couplings in an ionic liquid: nanoparticles responsible for the catalytic activity, Dalton Trans. 47 (2007) $5572-5581$

[22] J. Durand, E. Teuma, M. Gómez, An overview of palladium nanocatalysts: surface and molecular reactivity, Eur. J. Inorg. Chem. 2008 (2008) 3577-3586.

[23] J. Durand, E. Teuma, F. Malbosc, Y. Kihn, M. Gómez, Palladium nanoparticles immobilized in ionic liquid: an outstanding catalyst for the Suzuki C-C coupling, Catal. Commun. 9 (2008) 273-275.

[24] L. Rodríguez-Pérez, C. Pradel, P. Serp, M. Gómez, E. Teuma, Supported ionic liquid phase containing palladium nanoparticles on functionalized multiwalled carbon nanotubes: catalytic materials for sequential heck coupling/ hydrogenation process, ChemCatChem 3 (2011) 749-754.

[25] A.R. Kannurpatti, J.W. Anseth, C.N. Bowman, A study of the evolution of mechanical properties and structural heterogeneity of polymer networks formed by photopolymerizations of multifunctional (meth) acrylates, Polymer 39 (1998) 2507-2513.

[26] J.H. Ward, K. Furman, N.A. Peppas, Effect of monomer type and dangling end size on polymer network synthesis, J. Appl. Polym. Sci. 89 (2003) 3506-3519.

[27] S. Lin-Gibson, R.L. Jones, N.R. Washburn, F. Horkay, Structure-property relationships of photopolymerizable poly (ethylene glycol) dimethacrylate hydrogels, Macromolecules 38 (2005) 2897-2902.

[28] A.M. Ortega, S.E. Kasprzak, C.M. Yakacki, J. Diani, A.R. Greenberg, K. Gall, Structure property relationships in photopolymerizable polymer networks: effect of composition on the crosslinked structure and resulting thermomechanical properties of a (meth) acrylate-based system, J. Appl. Polym. Sci. 110 (2008) 1559-1572.

[29] F. Glorius, N-Heterocyclic Carbenes in Transition Metal Catalysis, SpringerVerlag, Berlin/Heidelberg, 2007.

[30] D.N. Muraviev, J. Macanás, J. Parrondo, M. Muñoz, A. Alonso, S. Alegret, M. Ortueta, F. Mijangos, Cation-exchange membrane as nanoreactor: Intermatrix synthesis of platinum-copper core-shell nanoparticles, React. Funct, Polym. 67 (2007) 1612-1621.

[31] J.L.G.A. Rivaton, Photodegradation of polyethersulfone and polysulfone, Polym. Degrad. Stab. 66 (1999) 385-403.

[32] J. Kiefer, J. Fries, A. Leipertz, Experimental vibrational study of imidazoliumbased ionic liquids: Raman and infrared spectra of 1-ethyl-3methylimidazolium bis (trifluoromethylsulfonyl) imide and 1-ethyl-3methylimidazolium ethylsulfate, Appl. Spectrosc. 61 (2007) 1306-1311.

[33] C. Emin, J-C. Remigy, J--F. Lahitte, Influence of UV grafting conditions and ge formation on the loading and stabilization of palladium nanoparticles in photografted polyethersulfone membrane for catalytic reactions, J. Membr. Sci. 455 (2014) 55-63.

[34] K.S. Khuong, W.H. Jones, W.A. Pryor, K.N. Houk, The mechanism of the selfinitiated thermal polymerization of styrene. Theoretical solution of a classic problem, J. Am. Chem. Soc. 127 (2005) 1265-1277.

[35] M. Atilhan, J. Jacquemin, D. Rooney, M. Khraisheh, S. Aparicio, Viscous behavior of imidazolium-based ionic liquids, Ind. Eng. Chem. Res. 52 (2013) 16774-16785.

[36] J. Jacquemin, P. Husson, A.A.H. Padua, V. Majer, Density and viscosity of several pure and water-saturated ionic liquids, Green Chem. 8 (2006) 172-180.

[37] S.K. Friedlander, A note on transport to spheres in stokes flow, AlChE J. 7 (1961) 347-348.

[38] E. Nagy, T. Blickle, A. Ujhidy, Spherical effect on mass transfer between fine solid particle and liquid accompanied by chemical reaction, Chem. Eng. Sci. 44 (1989) 198-201.

[39] R.G. Finke, Metal nanoparticles: synthesis, characterization and applications, Marcel Deker, New York, 2002.

[40] H. Seto, T. Yoneda, T. Morii, Y. Hoshino, Y. Miura, T. Murakami, Membrane reactor immobilized with palladium-loaded polymer nanogel for continuousflow Suzuki coupling reaction, AlChE J. 61 (2015) 582-589.

[41] V.W. Faria, D.G.M. Oliveira, M.H.S. Kurz, F.F. Gonçalves, C.W. Scheeren, G. R. Rosa, Palladium nanoparticles supported in a polymeric membrane: an efficient phosphine-free green catalyst for Suzuki-Miyaura reactions in water, RSC Adv, 4 (2015) 13446-13452.

[42] R. Aris, On the dispersion of a solute in a fluid flowing through a tube, Proc. R. Soc. London, Ser. A 235 (1956) 67-77.

[43] K.D. Nagy, B. Shen, T.F. Jamison, K.F. Jensen, Mixing and dispersion in smallscale flow systems, Org. Process Res. Dev. 16 (2012) 976-981.

[44] G. Taylor, Dispersion of soluble matter in solvent flowing slowly through a tube, Proc. R. Soc. London, Ser. A 219 (1953) 186-203.

[45] T. Westermann, E. Kretzschmar, F. Pitsch, T. Melin, Heat transfer and temperature profiles in flow-through catalytic membrane reactors, Chem. Eng. J. 155 (2009) 371-379.

[46] E. Nagy, 5 - Diffusive Plus Convective Mass Transport Through a Plane Membrane Layer, in: E. Nagy (Ed.), Basic Equations of the Mass Transport through a Membrane Layer, Elsevier, Oxford, 2012, pp. 121-156.

[47] L.-H. Cai, S. Panyukov, M. Rubinstein, Mobility of nonsticky nanoparticles in polymer liquids, Macromolecules 44 (2011) 7853-7863. 